\title{
ABADES Y MONASTERIOS EN LAS CORTES CASTELLANAS
}

\author{
ANA ARRANZ GUZMÁN \\ Universidad Complutense de Madrid
}

\begin{abstract}
SUMARIO
1. Introducción.- 2. La participación del clero regular en las Cortes castellanas.- 3 . Conclusiones.
\end{abstract}

\section{INTRODUCCIÓN}

Hace más de un siglo M. Colmeiro apuntó que el clero regular sólo había asistido durante la Edad Media a las Cortes de Burgos de $1315^{1}$. En 1897 W. Piskorski demostró que Colmeiro se había equivocado al reducir la intervención de los abades en las Cortes a una sola ocasión. El hispanófilo ruso, apoyándose casi exclusivamente en las menciones hechas de los titulares de monasterios en las actas, subrayó que su concurrencia había sido más nutrida. En concreto, para dicho historiador, el clero regular estuvo representado en las Cortes de 1271, 1274, 1295, 1305, 1315, 1322, 1325, 1371 y $1393^{2}$.

${ }^{\prime} \mathrm{M}$. ColmeIro, Introducción a las Cortes de los antiguos reinos de León y de Castilla (2 vols., Madrid, 1863), I, pp. 15-19.

${ }^{2}$ W. PISKORSKI, Las Cortes de Castilla en el periodo de transición de la Edad Media a la Moderna (1188-1520), Barcelona, 1977, p. 32. Este autor siguió la crónica de Alfonso X que data las Cortes de Burgos de 1272 en 1271, de ahí que situara en este último año la primera presencia en estas asambleas de abades y priores.

"Anuario de Estudios Medievales", 28 (1998) 
Desde principios de este siglo proliferaron en gran medida los estudios dedicados a los más diversos aspectos de las Cortes castellanas. La necesaria puesta al día de todos estos trabajos se llevó a cabo en una serie de congresos realizados en Burgos, Salamanca y León, respectivamente en los años 1986, 1987 y 1988, con motivo de la conmemoración del VIII centenario de las Cortes leonesas de 1188. Sin embargo, por regla general, la atención de los investigadores ha estado encaminada al estudio de otros asuntos distintos al de la participación del clero en estas asambleas. Ha habido, empero, excepciones como las de J.F. O'Callaghan a comienzos de la década de los ochenta ${ }^{3}$, o P. Linehan, con su participación en el mencionado congreso burgalés ${ }^{4}$. En ambos casos, sin embargo, el interés de los trabajos se centró más en ofrecer una panorámica global de la Iglesia castellana en relación con las Cortes que en dar a conocer los miembros del clero que concurrieron a las mismas, independientemente de su aparición o no en las actas.

Las lagunas y dudas existentes en torno a la representación eclesiástica en estas asambleas me llevaron, hace ya algunos años, a profundizar en el tema dando como resultado un estudio de carácter general ${ }^{5}$ y otro más estrechamente vinculado al clero regular ${ }^{6}$ que han servido de plataforma en la elaboración de estas páginas con el deseo de dar a conocer algunos datos más $\mathrm{y}$, sobre todo, de contribuir, aunque sea modestamente, en este homenaje a nuestra querida colega.

El primer problema que se plantea a la hora de intentar conocer cuales fueron los eclesiásticos que se hallaron presentes en Cortes es la parquedad informativa de los propios Ordenamientos y Cuadernos de peticiones. Las relaciones de representantes de los tres estamentos que acompañan a los monarcas en Cortes, incluidas al comienzo de todas las actas, sólo recogen en algunos casos la presencia de los religiosos. Así, en

${ }^{3}$ J.F. O'Callaghan, The ecclesiastical estate in the Cortes of Leon-Castile, 1250-1350, "The Catholic Historical Review", LXVII (1981), pp. 185-213.

${ }^{4} \mathrm{P}$. LINEHAN, Ecclesiastics and the Cortes of Castile and Leon, "Las Cortes de Castilla y León en la Edad Media", Valladolid, 1988, II, pp. 99-141.

${ }^{5}$ A. ARRANZ GuZMÁN, Reconstrucción y verificación de las Cortes castellano-leonesas: La participación del clero, "En la España Medieval", 13 (1990), pp. 33-132.

${ }^{6}$ A. Arranz Guzmán, Participación del clero regular en las Cortes castellanas, "Congreso Internacional sobre espacios y tiempos en el monacato", León, 1988. 
las de Zamora de $1274^{7}$; en las de Valladolid de 1295 , en cuyo Ordenamiento se especifica que asistió el abad fray Pedro de Valbuena ${ }^{8}$; en las de Medina del Campo de 1305'; en las de Burgos de 1315, en cuyas actas se aclara que concurrieron, además de los procuradores de todas "las yglesias e las órdenes", los abades fray García de San Salvador de Oña y fray Diego de San Millán de la Cogolla, a pesar de que sus nombres no aparezcan en las cartas entregadas al obispo de Burgos y al abad de Sahagún ${ }^{10}$; en las de Valladolid de 1322, donde, según refleja el Ordenamiento hecho a petición de los monasterios del reino de Castilla, los abades y abadesas debieron asistir en nutrido número ${ }^{11}$; en las de Valladolid de 1325 , donde si bien en las actas no aparece citado expresamente ningún $\mathrm{abad}^{12}$, se puede suponer la presencia de los de Celanova, Oña y Sahagún, o de sus procuradores, gracias a los originales destinados a estos abades del Ordenamiento otorgado a petición de los prelados; y en las de Madrid de $1393^{13}$. Por último hemos de subrayar que aunque el clero regular estuvo representado en las Cortes de Toro de 1371, la cita dada por Piskorski es incorrecta ${ }^{14}$.

Así pues, de acuerdo con los datos directos obtenidos de las actas de Cortes, el clero regular habría concurrido a las mismas tan solo en ocho ocasiones. Sin embargo, a través de las siguientes páginas se va a demostrar cómo la información proporcionada por otras fuentes permite asegurar que la presencia de los abades en las citadas asambleas fue significativamente más crecida. Estas fuentes documentales y bibliográficas aludidas son de naturaleza muy diversa. En primer lugar, y destacando sobre las demás, se

\footnotetext{
${ }^{7}$ En el comienzo del ordenamiento se menciona "el consejo quel rey demandó a los perlados e a los religiosos e a los ricos omes e a los alcaldes", Cortes de los antiguos reinos de León y de Castilla, ed. de la Real Academia de la Historia, I, Madrid, 1861, p. 87.

${ }^{8}$ Cortes, I, p. 133.

${ }^{9}$ Cortes, I, p. 179. Sólo se apunta que concurrieron "abades e omes de órdenes".

${ }^{10}$ Cortes, I, pp. 293-294.

"Cortes, I, p. 370. En concreto se dice que "los abbades e las abbadesas de los monasterios de rreligión de Castiella fizieron me -en las Cortes- sus petiziones aquellas que entendieron que les más cumplíe para guarda dellos e de los sus monasterios".

${ }^{12}$ Cortes, I, p. 389. No obstante, en el mencionado Ordenamiento se señala que estuvieron "arçobispos e obispos e abbades benditos e priores e maestres de las Ordenes" junto a los representantes de los otros dos estamentos.

${ }^{13}$ Cortes, II, p. 530

${ }^{14}$ En la página que señala Piskorski, la 241 del volumen II de las "Cortes", no aparece ninguna mención a abades o procuradores de monasterios asistentes a las Cortes de Toro de 1371 .
} 
encuentran las crónicas reales; en segundo lugar, los índices y catálogos documentales existentes sobre los monasterios castellanoleoneses; en tercer lugar, los documentos conservados en la sección de clero del Archivo Histórico Nacional; en último lugar, aunque con las reservas pertinentes, se han tenido en cuenta las noticias y comentarios proporcionados por la historiografía de los siglos XVII-XIX ${ }^{15}$.

\section{LA PARTICIPACION DEL CLERO REGULAR EN LAS CORTES CASTELLANAS}

Si bien es cierto que no se conservan actas de la reunión, todo parece indicar que en el año 1188 se celebraron Cortes en Carrión ${ }^{16}$. Según relata la Primera Crónica General de España, durante su realización Alfonso VIII armó caballeros a Alfonso IX de León y a Conrado de Hohenstaufen. Gracias a esta crónica y a la información proporcionada por algunos documentos es posible conocer cuales fueron los miembros del clero regular que acudieron a esta asamblea ${ }^{17}$. Entre ellos figura fray Juan, abad de Sahagún desde 1182. Además de por ser el titular de uno de los centros monásticos más importantes de la Península - hecho de por sí suficiente para entender su presencia en tan relevante acto-, su presencia en el mismo está refrendada por la estima que hacia él sentía el monarca castellano y, sobre todo, por el elevado número de documentos confirmatorios y de nuevas donaciones que Alfonso VIII le otorgó a lo largo de su estancia en Carrión, fechados entre el 4 de julio y el 26 de agosto de $1188^{18}$, y en uno de los cuales se puede leer: "Facta carta apud Carrionem, era $\mathrm{M}^{\mathrm{a}} \mathrm{CC}^{\mathrm{a}} \mathrm{XXVI}{ }^{\mathrm{a}}$, IIII nonas iulii et anno quo serenissimus rex prefatus Castella A. regem legionensem A. cingulum milicie in curia sua in Carrionem accinxit".

\footnotetext{
${ }^{15}$ Dichas reservas responden especialmente al hecho de que en no pocas ocasiones los historiadores de estos siglos afirman la presencia en Cortes de algún abad sin contar con un apoyo documental determinante.

${ }^{16}$ Como es sabido algunos autores prefieren considerar esta reunión como una Curia extraordinaria.

${ }^{17}$ Primera Crónica General, ed. de 1977, p. 677. Ver también J. GONZÁLEZ, El reino de Castilla en la época de Alfonso VIII, Madrid, 1960, II, docs. 505 y 506, pp. 868-873.

${ }^{18}$ EsCalona, Historia del Real Monasterio de Sahagún, Madrid, 1782, p. 124; y Vignau, Indice de los documentos del Monasterio de Sahagún, Madrid, 1874, pp. 38-40.
} 
La asamblea vallisoletana de 1217 ha ofrecido a algunos autores dudas terminológicas y relativas a su naturaleza que les ha llevado a no considerarla como una reunión de Cortes ${ }^{19}$. Por nuestra parte consideramos que sí se puede usar el nombre de Cortes para designar esta asamblea, pues se dieron las suficientes circunstancias y acontecimientos para ello: asistieron los tres estados; en ella se produjo el notable acontecimiento de la coronación de Fernando III; y el nuevo monarca aprovechó la situación para efectuar importantes promesas, como la de respetar los derechos de los concejos y los privilegios de la nobleza y del clero, o la de no tomar antes de los veinte años ninguna decisión de gravedad sin realizar una consulta previa. En este caso además la inexistencia de convocatoria por escrito no obedecía más que a la urgencia de la reina por ganar tiempo al de Lara. Aunque la importancia de esta asamblea pudiera llevar a pensar que en ésta debió haber una nutrida representación del clero, de hecho sólo se conoce, merced a la Crónica Latina y a la Primera Crónica General, la presencia en la asamblea del abad de Valladolid $^{20}$. En realidad la noticia ofrecida por ambas crónicas no es del todo exacta puesto que en 1217, y todavía durante dos años más, fray Juan Domínguez ocuparía la dignidad de abad de Santander. Además, pensamos que su asistencia a esta reunión no obedeció a su condición eclesiástica sino al hecho de haber sido elegido canciller en funciones de don Fernando por parte de la reina.

El ordenamiento de las Cortes de Burgos de 1272, celebradas en un contexto de descontento y rebeldía hacia Alfonso X, no se ha conservado, aunque sí ha llegado hasta nosotros un documento relativo a los servicios concedidos allí al monarca ${ }^{21}$. La única fuente de información respecto a la participación del clero regular en esta asamblea es la crónica real, donde se afirma que estuvieron "el abad de Cueva Rubias, fray Tello; e de las órdenes de Sant Francisco, e fray Diego Ruiz e fray Juan Reveca; e de los predicadores fray Martín, doctor de Palencia, e fray Domingo de Palencia"22. Al igual que en el caso anterior del abad de Valladolid, hemos de señalar que la presencia en estas Cortes del abad de Covarrubias, fray Fernando Ruiz o Rodríguez de las Cabañas, no era casual, ya que fue uno de los eclesiásticos

\footnotetext{
${ }^{19}$ J. GonZÁLEZ, Reinado y diplomas de Fernando III, I, Córdoba, 1980, p. 238.

${ }^{20}$ Crónica Latina de los Reyes de Castilla, ed. de L. Charlo Brea, Cádiz, 1984, pp. 69-70.

${ }^{21} B$ iblioteca del Palacio Real de Madrid, Ms. II-699, fol. $176 \mathrm{r}-\mathrm{v}$.

${ }^{22}$ Crónica de Alfonso X, ed. de la B.A.E., Madrid, 1953, cap. XXVI, p. 23.
} 
que más hizo en favor del Rey Sabio, intentando reducir a los rebeldes y siendo un firme defensor de las aspiraciones del monarca a la corona imperial $^{23}$

Tampoco se conserva el Ordenamiento original de las Cortes zamoranas de 1274 , aunque sí se conoce una relación abreviada del mismo contenida en un manuscrito del siglo XVI que fue publicado en su día por la Real Academia de la Historia ${ }^{24}$. Basándose en su encabezamiento Piskorski afirmó que en esta ocasión el clero regular estuvo representado en la asamblea, criterio que compartimos a pesar de que hasta el momento no hayamos encontrado otros documentos que lo corroboren.

Como ya apuntamos, en el Ordenamiento de las Cortes vallisoletanas de 1295 publicado por la Academia sólo se señala la presencia del abad de Valbuena, fray Pedro. Su asistencia no es de extrañar si se tiene en cuenta que el mencionado cenobio fue uno de los más beneficiados por los monarcas desde su fundación en 1143 y especialmente desde que Alfonso X, siendo aún infante, lo tomara bajo su protección ${ }^{25}$. Aunque el abad Pedro de Sahagún, que dirigió el monasterio entre 1287 y 1300, no aparece en el Ordenamiento, consta que estuvo en estas Cortes gracias a un documento en el que figura su nombre junto a los del arzobispo de Toledo, los obispos de Astorga, Badajoz, Osma, Palencia y Tuy, y el abad de Valbuena, quienes elevaban una queja conjunta al monarca por "los muchos agravamientos que habían recibido de los reyes en los tiempos pasados" 26 .

De las cortes de Medina de 1305 existen tres Ordenamientos: los concedidos al reino de León, a los concejos de Castilla y a los de las Extremaduras y el reino de Toledo $^{27}$. No creemos que la asistencia del clero a esta reunión fuese muy numerosa aunque se encuentre a la casi

\footnotetext{
${ }^{23}$ Sobre las actividades de este abad y sus relaciones con Alfonso X, ver L. SERRANO, Cartulario del Infantado de Covarrubias, Valladolid, 1907, pp. LXIV-LXIX.

${ }^{24}$ Cortes, I, p. 87 . Ver nota 7.

${ }^{25}$ Los privilegios otorgados a los sucesivos abades de Valbuena desde Alfonso VII a Pedro I se encuentran en el Archivo Histórico Nacional, sección de Clero, carpetas 3440-3441.

${ }^{26}$ Ed. A. Benavides, Memorias de Don Fernando IV de Castilla, Madrid, 1860, II, doc. XIII, p. 41. Ante esta queja el día 6 de agosto el rey se comprometió a no tomar bienes eclesiásticos cuando muriesen sus titulares, a no intervenir en la elección de dignidades eclesiásticas y a no pedir tributos ni mandar prender a los clérigos. Ver además A. ARRANZ GUZMÁN, Los enfrentamientos entre concejos y poderes eclesiásticos en las Cortes castellanas. ¿sincronización de los conflictos?, "Hispania", XLIX (1989), pp. 5-68.

${ }^{27}$ Cortes, I, pp. 169, 172 y 179.
} 
totalidad de los prelados del reino confirmando un privilegio otorgado en estas Cortes al concejo de $\mathrm{Haro}^{28}$. En cambio sí podemos asegurar la presencia de algunos miembros del clero regular junto a la del arzobispo de Toledo y los obispos de Astorga y Coria, ya que los Ordenamientos recogen de un modo genérico su presencia. Aunque esta referencia hace imposible precisar qué abades concurrieron a la asamblea, cabe imaginar que estarían presentes los de los monasterios más importantes.

El protocolo de las Cortes palentinas de 1313 recoge los nombres de algunos de los prelados asistentes a la asamblea pero nada dice respecto a la presencia de abades. Sin embargo, en función del contenido de la petición número cuarenta y cuatro del Ordenamiento parece seguro que acudieron a estas Cortes sendos procuradores de los monasterios de Oña y Aguilar. En esta ocasión la presencia de los dos cenobios no estuvo motivada como en otros casos por asuntos concernientes al conjunto del estamento eclesiástico, sino por una razón tan particular como era la usurpación de algunas de sus heredades: "Otrossí nos pidieron que entregássemos al obispo de Calahorra la villa e el castillo de Alvelda que Garci Martín, chantre su procurador, querelló quel teníen tomado por fuerça, et el monasterio de Onna quel entreguemos casas e heredamientos que dizen quel tomaron, e el monasterio de Aguilar esso mismo. Tenemoslo por bien e otorgamos gelo" 29 .

Las primeras Cortes celebradas con verdadera autoridad desde la muerte de Fernando IV fueron las de Burgos de 1315. Todos los que deseaban confirmar sus privilegios o adquirir nuevas mercedes debían acudir a ellas, por lo que es de suponer que concurriera una amplia representación del clero regular. Así parecen demostrarlo los múltiples privilegios y confirmaciones otorgados en esta asamblea a los procuradores de monasterios como La Vid, Arlanza, Monfero, Sobrado o Santa $\mathrm{Cruz}^{30}$. Sin embargo, en el ordenamiento hecho a petición de los prelados sólo se nombra a los abades de San Millán de la Cogolla y San Salvador de Oña ${ }^{31}$.

\footnotetext{
${ }^{28}$ Cortes, I, p. 178. Sin duda su presencia en el documento se debía a una mera fórmula cancilleresca.

${ }^{29}$ Cortes, I, p. 245.

${ }^{30}$ Respectivamente, M. GaIBRoIS, Historia del reinado de Sancho IV de Castilla, III, Madrid, 1928, doc. 462; E. GONZÁLEZ CRESPO, Colección documental de Alfonso XI. Diplomas reales conservados en el Archivo Histórico Nacional. Sección de Clero. Pergaminos, Madrid, 1985, docs. 30 y 38; y A.H.N., clero, carpeta 546, n 12, Sobrado (La Coruña); y carpeta 1744, n 12, Santa Cruz (Palencia).

${ }^{31}$ Cortes, I, p. 293.
} 
Estos eran, respectivamente, fray Diego y fray García, quienes tenían un gran interés en hacerse reconocer sus propiedades y autoridad, que tanto peligro habían corrido durante los años pasados ${ }^{32}$. La respuesta a sus protestas fue inmediata y así, por ejemplo, el 20 de julio Alfonso XI ordenaba, ante la denuncia por parte del abad de Oña de los abusos cometidos por los castelleros de Frías, que no se siguiera demandando ropa, leña o carne a los realengos y abadengos de dicho monasterio ${ }^{33}$.

El ordenamiento de prelados, como ya dijimos, no apunta la presencia de ningún abad más de los mencionados, al igual que tampoco lo hace la crónica. No obstante, gracias a una petición incluida en dicho ordenamiento se puede deducir que el abad de Sahagún debió mandar algún procurador a las cortes burgalesas de 1315 para que en su nombre denunciara ante el rey los atropellos que estaba padeciendo: "Otrosí a lo que me pidieron que los perlados e abbades que están desposeidos de sus sennoríos e de sus lugares e de sus derechos e de sus bienes e sennaladamient el obispo de Palencia e el obispo de Calahorra e el obispo de Badajoz e el obispo de Lugo e el monesterio de Sant Fagunt, que sean entregados e restituidos sin alongamiento. Tengolo por bien e por derecho e mandar lo he assí facer" ${ }^{34}$. En efecto, el abad fray Nicolás no asistió a las cortes personalmente pero encargó a dos representantes que llevaran sus demandas a la asamblea. Según se recoge en un documento fechado en Medina el 26 de julio de 1326 estos procuradores eran fray Alfonso, limosnero mayor de Sahagún, y don Juan, sacristán de San Mancio ${ }^{35}$. En esos momentos el abad se hallaba en una situación verdaderamente problemática con los del concejo de la villa, pero los tutores pondrían fin, al menos momentáneamente, a sus querellas $^{36}$. En primer lugar los mencionados tutores de Alfonso XI extendieron, en forma de carta para enviársela a fray Nicolás, el ordenamiento de 1315 hecho a petición de los prelados. Más tarde, el 2 de abril de 1316, mandaron

\footnotetext{
${ }^{32}$ Baste con recordar el hecho de que a causa del bandolerismo existente, el monasterio de San Millán se vio obligado en 1299 a encomendar la tutela de sus derechos y posesiones al poderoso Lope Díaz de Haro, L. Serrano, Cartulario de San Millán de la Cogolla, Madrid, 1930, p. XCIX.

${ }^{33} \mathrm{AHN}$, clero, carpeta 307, n” 20. Ed. E. GonZÁlez CRESPO, op. cit., doc. 31, pp. 62-63.

${ }^{34}$ Cortes, I, p. 296.

${ }^{35} \mathrm{AHN}$, clero, carpeta 926, n” 22.

${ }^{36} \mathrm{El} 2$ de septiembre de 1304 los burgueses habían logrado que Fernando IV retirara al abad y al monasterio numerosas prerrogativas en su villa de señorío, como la facultad de pone alcaldes y merinos o la de custodiar las llaves de la ciudad, EsCALONA, op. cit., pp. 163-166.
} 
otra carta ordenando cumplir la sentencia dada por el tutor real don Juan en la que, fundándose en un documento de Fernando IV, confirmaba al abad de Sahagún la posesión de las llaves de la villa, su derecho a poner alcaldes y la necesidad de su autorización para la entrada del merino en su jurisdicción, precisamente las tres capacidades de las que había sido desposeido por el concejo $^{37}$.

En el año 1318 se convocaron Cortes por separado. Los leoneses y los de la Extremadura se reunieron en Medina del Campo, y los castellanos en Valladolid. De los dos Ordenamientos tan solo se conserva el otorgado en Medina, que no contiene la referencia a ningún abad. A pesar de ello, es conocida la asistencia del titular de Sahagún, fray Martín, a las Cortes vallisoletanas merced a un documento expedido por Alfonso XI a los ciudadanos de Sahagún para que respetasen los derechos y las posesiones del $\mathrm{abad}^{38}$. Esta orden real no tendría el éxito deseado pues los burgueses, lejos de someterse a ella, se amotinaron de nuevo en otoño derribando las casas y propiedades del monasterio, talando sus campos y resistiéndose a los alcaldes elegidos por el abad. La virulencia de estos hechos y la persistencia del enfrentamiento explican por sí mismas las continuas quejas de los sucesivos titulares del monasterio y su presencia regular en las reuniones de Cortes.

En las Cortes de Valladolid de 1322, últimas de la minoridad de Alfonso XI, el tutor don Juan el Tuerto otorgó un Ordenamiento a los monasterios del reino. Pero ni en éste ni en el concedido a los concejos por don Felipe se menciona otro abad que el titular de Oña, en esos momentos fray Pedro de Valdivia. No obstante, resulta significativo que en el ordenamiento de los monasterios se especifique que estaba hecho también a petición de las abadesas. Esta circunstancia se debía probablemente al conflicto planteado por los procuradores de las ciudades al quejarse de la donación efectuada por la reina María de Molina al convento de las Huelgas de Valladolid del lugar de Villa García, que "ssiempre ffue de los rreys"39.

\footnotetext{
${ }^{37}$ Vignau, op. cit., p. 67.

${ }^{38}$ ESCALONA, op. cit., pp. 645-646. En este documento se lee que “...estando él (el abad) agora acá en Valladolid en las Cortes ... pidió merced a mí e a los míos tutores...".

${ }^{39}$ Cortes, I, pp. 345-346. Al incendiarse el primitivo monasterio en 1282, María de Molina había cedido a la comunidad su palacio y le había dotado con numerosos bienes y privilegios. Por otro lado, como es sabido, la abadesa de las Huelgas de Valladolid poseía muchos lugares en señorío, entre ellos el de Zaratán.
} 
Ante la amenaza de perder esta posesión resulta muy probable que la abadesa de las Huelgas hubiera enviado un representante a las Cortes para defender la donación de la reina difunta, aunque esta suposición no se puede confirmar al no haberse encontrado la imprescindible carta de procuración.

Las Cortes de Valladolid de 1325 poseen especial interés por ser frontera entre una etapa de debilitamiento de la corona y otra de vigorización de la autoridad real. El hecho de que Alfonso XI fuera a tomar personalmente las riendas del gobierno en esta asamblea motivó que el estamento eclesiástico acudiera a ella de forma masiva. De este modo, en las actas se subraya que el ordo clerical se hallaba representado en su totalidad, puntualizándose que a pesar de no haber asistido algunos prelados, otros prelados o sus procuradores hablaban por ellos. No obstante hemos de decir también que salvo en el caso de los tres abades relacionados con las copias del Ordenamiento, fray García de Oña, fray Martín de Sahagún y fray Juan Pérez de Celanova, los Cuadernos no ofrecen nombre alguno ${ }^{40}$. La crónica, por su parte, sólo menciona al abad de Santander fray Nuño Pérez, que había sido canciller y consejero de la reina María de Molina ${ }^{41}$.

Aunque sin ser Cortes, no debe pasarse por alto la reunión mantenida por el monarca con el estamento eclesiástico en Medina del Campo el año $1326^{42}$. Los temas allí tratados fueron los mismos que en las Cortes de Valladolid, lo que hace suponer que el estamento clerical no había quedado satisfecho en 1325. Respecto a la asistencia del clero regular nada se dice en el privilegio otorgado allí el 28 de julio. Al margen de los logros obtenidos por el clero en esta reunión, resulta interesante destacar la resolución que adoptó Alfonso XI tras haber oído a los procuradores del abad de Sahagún y a los del concejo de la villa, y que consistió en permitir que el concejo participase en la elección de los alcaldes y pasase a custodiar

${ }^{40}$ Cortes, I, p. 390. Biblioteca Nacional, manuscritos, 13.098, fols. 116 y 125.

${ }^{41}$ Crónica de Alfonso XI, ed. de la BAE, Madrid, 1953, cap. XXXIX, p. 199.

${ }^{42}$ Son numerosas las copias conservadas del ordenamiento hecho en Medina sobre los bienes realengos pasados al abadengo: A.C. de Burgos, vol. 5 , parte $2^{a}$, fol. $10 ;$ A.C. de Cuenca, doc 331; A.C. de León, doc. 1188; A.C. de Oviedo, serie B, carp. 6, n² 20; A.C. de Salamanca, caja 6, leg. 2, n⿳ 33; A.C. de Zamora, leg. 10, n⿳0 6; A.H.N., microfilm del A.C. de Valladolid, caja 1557; Biblioteca Nacional, manuscritos, 13.097, fols. $125 \mathrm{r}-129 \mathrm{v}$; Biblioteca de Santa Cruz de Valladolid, ms. 21, fols. $163 \mathrm{r}-216 \mathrm{v}$. El manuscrito fue publicado por A. LÓPEZ FERREIRO, Historia de la Santa A. M. Iglesia de Santiago de Compostela, Santiago, 1903, VI, pp. 61-71. Para un análisis más detallado de este asunto ver A. ARRANZ GUZMÁN El tercer estado castellano ante las relaciones realengo-abadengo. Siglos XIII-XV, "Hispania", XLIX (1989), pp. 443-476. 
las llaves de la villa, facultades que anteriormente sólo correspondían al $\mathrm{abad}^{43}$.

En el año 1345 se celebraron Cortes por separado en Alcalá de Henares, Burgos y León, siendo conocidos los Ordenamientos realizados en las dos primeras ciudades ${ }^{44}$. Sobre la asamblea de León conviene decir que además de poseer noticias de ella gracias a diversos documentos ${ }^{45}$, C. Guillén planteó la posibilidad de que el Cuaderno de Cortes leonés fechado en 1349 en la publicación de la Real Academia de la Historia fuera en realidad el otorgado en $1345^{46}$. En cualquier caso, nada se dice en los Cuadernos respecto a los representantes del clero que concurrieron, pues lo único que se menciona es que fueron "algunos perlados". A pesar de ello, existen noticias de la presencia en estas Cortes de algún abad o de su procurador. Berganza, por ejemplo, recogió en sus "Antigüedades de España" la asistencia del abad de Cardeña fray Juan de Mecerreyes. Este autor fundamentó su afirmación en que dicho abad, junto con otros miembros del alto clero y ricos hombres, ante el deseo del rey de quitar las exenciones existentes por su "mucha necesidad de moneda", presentó "a su magestad en las Cortes que tuvo en Burgos las razones que avía para que mandassen guardar las inmunidades y franquezas que los reyes avían concedido a los concejos y cabildos". En concreto fray Juan de Mecerreyes defendió los privilegios de su monasterio ante el monarca, quien una vez examinados, mandó a sus oficiales que no cobrasen los tributos de portazgo, montazgo y cancillería en los lugares del monasterio ${ }^{47}$. La presencia física, o a través de procuradores, de otros abades resulta más difícil demostrar,

\footnotetext{
${ }^{43}$ ESCALONA, op. cit., p. 167; y Vignau, op. cit., p. 68. 280

${ }^{44}$ Cortes, I, pp. 477 y 483 . Biblioteca del Palacio Real de Madrid, Ms. II-699, fols. 8 y

${ }^{45}$ Uno de estos documentos consiste en una confirmación al abad de Cardeña de sus privilegios, F. BERGANZA, Antigüedades de España propugnadas en las noticias de sus reyes en la Crónica del Real Monasterio de San Pedro de Cardeña, Madrid, 1719-1721, II, pp. 502503 . Otro de ellos es una provisión otorgada por el rey a petición de los procuradores leoneses, que informa además de que las Cortes o Ayuntamiento de León se realizaron antes del 24 de junio, fecha de expedición del documento, NIETO GUTIÉRREZ, Catálogo de los documentos del Archivo Municipal de León, León, 1927, nº 88

${ }^{46} \mathrm{C}$. GUILLÉN, ¿Dos ayuntamientos en León a finales del reinado de Alfonso XI?: 1345 y 1349, "En la España Medieval”, 5 (1984), pp. 501-513. Este autor basa su afirmación en varias circunstancias: la ausencia de referencias a las Cortes de 1348; la similitud de estructura entre los tres Cuadernos; la referencia a la persona de Juan Hurtado de Mendoza; y las menciones documentales sobre el ayuntamiento leonés de 1345.
}

${ }^{47}$ F. BERGANZA, op. cit., I, p. 202; y II, pp. 502-503. 
pero en función de la documentación conservada creemos que el abad de Sahagún envió a su camarero como procurador a alguna de estas reuniones, a la que también habrían concurrido los procuradores del concejo de la misma villa, para solucionar uno de los continuos pleitos que mantenían ${ }^{48}$.

De las Cortes de 1351 se conservan varios Cuadernos, pero ni en ellos ni en la crónica se recoge la presencia de abades ${ }^{49}$. Mas en esta ocasión gracias al importantísimo número de documentos conservados, no nos cabe duda de que el clero regular estuvo representado en las mismas. Además por ser éstas las primeras Cortes de Pedro I era de esperar que la asistencia del clero fuera masiva, ya que todos deseaban ver confirmados sus privilegios y, si era posible, obtener otros nuevos. Hemos llegado a contabilizar más de trescientos documentos expedidos a lo largo de la celebración de estas Cortes, entre junio de 1351 y marzo de 1352, que tenían como destinatarios a los titulares de monasterios de todo el reino. Esto, por supuesto, no confirma la presencia del conjunto de sus abades o de sus procuradores, puesto que como sabemos el de uno de ellos podía acudir en representación de varios cenobios. Entre otros los monasterios beneficiados fueron los siguientes: Aguilar de Campoo, Carracedo, Herrera, Matallana, El Moral, Palazuelos, Retuerta, San Andrés de Espinareda, San Esteban de Nogales, San Esteban de Ribas de Sil, San Isidoro de León, San Julián de Samos, San Justo de Tojos Outos, San Nicolás el Real de Palencia, San Pedro de Arlanza, San Pelayo de Oviedo, San Salvador de Chantada, San Vicente del Pino, Sancti Spiritus de Toro, Santa Clara de Castrojeriz, Santa María de Arévalo, Santa María de Bujedo, Santa María de Nájera, Santa María de Oya, Santa María de Rioseco, Santa María de Trianos, Santa María de la Vega de Saldaña, Santa María de la Vid, Santo Domingo el Real de Madrid, Santo Domingo de Silos, Sobrado, Valdediós, y Villanueva de Lorenzano $^{50}$.

Atendiendo al número de documentos destinados a cada monasterio, a quiénes eran sus titulares y a los asuntos tratados en las cartas expedidas, al margen de la mera confirmación de privilegios, parece seguro que

\footnotetext{
${ }^{48}$ Ver al respecto el documento catalogado por ESCALONA, op. cit., pp. 74-75.

${ }^{49}$ Cortes, II, pp. 1, 48, 91, 102, 111, 124 y 132. Del cuaderno de peticiones de los prelados, con fecha 30 de octubre, existe una copia en el A.C. de Salamanca, caja 43, leg. 2, no 73. Crónica de Pedro I, ed. de la BAE, Madrid, 1953, pp. 417-418.

${ }^{50}$ Las referencias de los documentos en L.V. Díaz MARTín, Itinerario de Pedro I de Castilla. Estudio y regesta, Valladolid, 1975.
} 
concurrieron a las Cortes los siguientes abades: el de Santa María de Osera, fray Domingo, a quien interesaba poner fin al pleito sostenido con el alcalde de Chantada; el de San Salvador de Oña, cuyo monasterio fue tomado por Pedro I bajo su protección en estas Cortes; el de Valbuena quien, tras exponer al monarca cómo había repercutido la crisis demográfica en su cenobio obtuvo su favor; un procurador de la abadesa de las Huelgas de Burgos; y si damos por buena la noticia ofrecida por Berganza, también habría estado presente el abad de San Pedro de Cardeña, fray Juan de Mecerreyes $^{51}$.

No obstante, de la presencia de la que mayor seguridad tenemos es de la del abad de Sahagún fray Diego, quien en esos momentos mantenía un pleito con el obispo leonés. Resulta sumamente interesante que Escalona al hablar de Pedro I, aun sin intentar entrar en polémica sobre su crueldad o justicia, diga que este monarca "dio claras pruebas de ser piadoso, clemente y benigno". Lo que desde luego se puede observar a través de los numerosos documentos existentes es la cordial relación entre el monarca y el abad fray Diego hasta la muerte del eclesiástico en 1357. De la asistencia de fray Diego a estas Cortes de 1351 dan noticia varios documentos. El primero, y más relevante dada su excepcionalidad, es una carta de Pedro I fechada en Illescas el 15 de abril por la que convocaba al abad a las Cortes de Valladolid y le rogaba que no acudiese en compañía de más de seis hombres a caballo puesto que había limitado el número de acompañantes de los asistentes para que no faltaran hospedajes ni subsistencias ${ }^{52}$. El segundo documento consiste en otra carta del monarca en la que a petición de fray Diego mandaba insertar la donación de varias villas en el monte Tronisco hecha al monasterio de Sahagún por Alfonso III y su mujer. Existen además varios privilegios otorgados al abad y fechados entre septiembre de 1351 y enero de $1352^{53}$.

\footnotetext{
${ }^{51}$ AHN, clero, carpeta $1547, n^{\circ} 17$, (Santa María de Osera); carpeta $313, n^{\circ} 9$ y 13, (San Salvador de Oña); y carpeta $3441, \mathrm{n}^{\circ} 16$ y 17 , (Valbuena). Sobre las Huelgas, RoDRíGUEZ LÓPEZ, El Real Monasterio de las Huelgas de Burgos, Burgos, 1907, I, doc. 150, p. 551. Sobre Cardeña, F. Berganza, op. cit., p. 205.

${ }^{52} \mathrm{AHN}$, sigilografía, caja $17, \mathrm{n}^{\circ} 12$. Ed. J.B. SiTGES, Las mujeres del rey Don Pedro I de Castilla, Madrid, 1910, pp. 183-184.

${ }^{53}$ No cabe duda de que Pedro I se volcó en favorecer al monasterio de Sahagún, pero también es cierto que no dudó en solicitar su ayuda económica cuando la situación lo requería. Así, por ejemplo, en 1358 pidió al abad fray Alonso Valero "una suma crecida de maravedíes para los gastos de la guerra que hacía al rey de Aragón”, EsCALONA, op. cit., p. 174.
} 
Aunque durante las Cortes de 1367 se confirmaron los privilegios de diversos monasterios, no creemos que asistiera a esta asamblea ningún miembro del clero regular. En cambio de lo que no cabe duda es de su presencia en la reunión celebrada en Toro en 1371 según lo señala el mismo Ordenamiento: "por rrazón que en las Cortes que nos fezimos en Toro los arçobispos e obispos e los procuradores de las eglesias e monesterios de nuestros rregnos nos fizieron sus peticiones a las quales nos rrespondimos en esta manera" 54 . Desgraciadamente este Ordenamiento no menciona nombre alguno y para saber con certeza qué abades concurrieron tampoco se pueden tener en cuenta las cartas que se expidieron entonces en favor suyo, ya que se trata de simples confirmaciones de privilegios de épocas anteriores. A pesar de todo, y en función del contenido de algunos documentos - no de los meramente confirmatorios - así como del prestigio de algunos monasterios, nos atrevemos a señalar como posibles asistentes a los abades de Cardeña, Oña, Sahagún y Valdediós. El último de los abades citados, por ejemplo, recibiría de Enrique II nuevos privilegios de carácter económico para su comunidad ${ }^{55}$.

En las actas publicadas de las Cortes de Soria de 1380 no se refleja la presencia del clero regular, pero nos consta que ciertos abades presentaron en ellas una queja contra los encomenderos de sus respectivos monasterios, acusándoles de que lejos de actuar como protectores eran auténticos usurpadores de los bienes monásticos. Ante tales protestas Juan I declaró que sólo tendrían validez las encomiendas otorgadas directamente por él, las contraídas voluntariamente por abades y obispos y las heredadas de los fundadores, anulando definitivamente el resto. El monarca también dispuso que las reclamaciones sobre este asunto se hicieran en Medina del Campo ante un tribunal compuesto por cuatro jueces. La documentación conservada permite conocer los nombres de aquellos oficiales y nobles que mantenían una actitud tan perjudicial para las comunidades monásticas. Entre ellos destacaban Pedro Fernández de Velasco, que trataba como propios a los vasallos de Oña, ocupaba dieciséis lugares pertenecientes a Silos y usurpaba Quintanilla de San García a las Bernardas de Cañas; Alvaro Pérez de Sotomayor que oprimía al monasterio de Armenteira; y Pedro Ruiz de

\footnotetext{
${ }^{54}$ Cortes, II, p. 244. p. 55 .

${ }_{55}^{55}$ Un extracto de este documento en Jovellanos, Colección de Asturias, Madrid, 1948, II,
} 
Sarmiento, adelantado mayor de Galicia, que detentaba propiedades de Cardeña y se titulaba encomendero de Celanova, San Clodio de Ribadavia y Santa Comba de Naves. Entre los usurpadores se encontraban también tres parientes del rey, don Pedro, conde de Trastámara, don Fadrique, duque de Benavente y don Alfonso, conde de Noreña.

La gravedad de los problemas expuestos motivó que a la mencionada reunión de Medina del Campo acudieran para realizar las oportunas reclamaciones todos los titulares de los monasterios afectados o cuando menos sus respectivos representantes ${ }^{56}$. La abundante documentación conservada permite conocer que las quejas de los monjes de Aguilar de Campoo, Osera, San Juan del Poyo, San Pedro de Arlanza, San Salvador de Oña, Santa María de Armenteira, Santo Domingo de Silos y de la abadesa de las Huelgas de Burgos, fueron oídas y solucionadas inmediatamente ${ }^{57}$. También se atendieron las reclamaciones de San Clodio de Ribadavia, San Salvador de Lerez, Santa María de Sobrado y Santo Toribio de Liébana ${ }^{58}$. Las resoluciones tomadas en este Ayuntamiento de Medina se mantendrían a lo largo de todo el reinado de Juan I, como lo demuestra el hecho de que se remitieran a ellas en las Cortes de Segovia de 1386 y en las de Guadalajara de $1390^{59}$.

A partir del reinado de Juan I puede decirse que el clero regular dejó de asistir a las reuniones de Cortes. En dos ocasiones, en la asamblea celebrada en Madrid en 1393 por Enrique III y en la llevada a cabo en Segovia en 1407 por los tutores de Juan II, los Ordenamientos y las crónicas citan como presentes a alguno de sus miembros ${ }^{60}$. Pero no hay que llevarse a engaño, ya que estos personajes acudieron a las citadas Cortes no en su calidad de eclesiásticos sino en función del desempeño de diversas tareas administrativas en la corte. Sirva como ejemplo el caso del abad de Husillos,

\footnotetext{
${ }^{56}$ Alguno de los monasterios, como el de Santa María de Melón, ya había solucionado sus problemas previamente a la reunión de Medina del Campo, L. SUÁrEz, Historia del reinado de Juan I de Castilla, Madrid, 1982, II, doc. 140.

${ }^{57}$ L. SuÁrez Fernández, op. cit., docs. 173, 193, 194, 197, 223 y 225. Rodríguez LÓPEZ, op. cit., doc. 153.

${ }^{58} \mathrm{AHN}$, clero, carpeta 548, n" 18; carpeta 1920, n"10; y Registro de escrituras de San Clodio de Ribadavia, fol. $28 \mathrm{r}$

${ }^{59}$ Cortes, II, pp. 348 y 458.

${ }^{60}$ Cortes, III, p. 530. Crónica de Juan II, ed. de la BAE, Madrid, 1953, p. 27.
} 
fray Juan González, al que se cita en las actas de 1393 pero cuya presencia en esa reunión se debe a su pertenencia a la Audiencia Real.

\section{CONCLUSIONES}

Tras haber ofrecido una relación documentada de la presencia del clero regular en las Cortes medievales castellanas no resta sino resumir las conclusiones a las que hemos llegado:

-Frente a las ocho ocasiones en las que la asistencia del clero regular a Cortes había quedado recogida en los Ordenamientos y Cuadernos de peticiones, se ha podido comprobar cómo éste acudió a estas asambleas al menos en nueve ocasiones más. De este modo, la presencia documentada de los abades o sus procuradores se extiende a las siguientes Cortes: 1188, $1217,1272,1274,1295,1305,1313,1315,1318,1322,1325,1345,1351$, $1371,1380,1393$ y 1407 , a las que habría que sumar los ayuntamientos particulares de Medina del Campo de 1326 y 1380.

- La asistencia de los abades a estas asambleas fue muy escasa en comparación con la de los arzobispos y obispos.

- Las razones que llevaron a los titulares de los monasterios a acudir a las Cortes hasta finales del siglo XIV fueron muy variadas: la necesidad de obtener confirmación de los privilegios de que gozaba su comunidad; la búsqueda del amparo regio ante los conflictos particulares; el interés por solucionar los problemas que afectaban al conjunto del ordo clerical; su convocatoria por el monarca; y la ostentación de cargos extraeclesiásticos en la corte, único motivo que prevalecería en el siglo XV.

- Los abades que con mayor frecuencia asistían a las asambleas del reino eran los titulares de los cenobios más importantes como Cardeña, Oña o Sahagún. Esta presencia se acentuaba en el caso de que el monasterio mantuviera abierto algún conflicto de entidad, como sucedió precisamente en el caso de Sahagún.

- Las confirmaciones de los diferentes privilegios de que gozaban los monasterios fueron concedidas mayoritariamente por los monarcas en las primeras Cortes celebradas en cada reinado. Esta circunstancia no implica en ningún caso la presencia de los abades de todo el reino en la asamblea que inauguraba cada nueva etapa de gobierno pues, como queda reflejado en algunos Ordenamientos, resultaba muy frecuente que un mismo procurador atendiera simultáneamente los intereses de varios monasterios. 
- Los temas que el clero regular trató más asiduamente en Cortes fueron los relacionados con las usurpaciones jurisdiccionales y territoriales llevadas a cabo en los abadengos monásticos por parte de la nobleza y los altos oficiales regios; y los relativos a las contiendas de todo tipo mantenidas con los concejos y los laicos en general.

- Por último, cabe señalar que la progresiva ausencia en las Cortes del clero regular hay que inscribirla en la actitud desarrollada por el conjunto del estamento eclesiástico ante el lento pero imparable desplazamiento del poder y de la capacidad de decisión desde estas asambleas al propio monarca y al Consejo Real.

\section{RÉSUMÉ}

Dans le présent travail nous analysons la relation des abbés concourents à les "Cortes" de Castille et de Leon, depuis l'année 1188 jusqu'à la fin du XIV siècle, quand les titulaires des monastères laisserent d'assister pour causes exclusivement ecclésiastiques. Pour l'élaboration de cet étude, nous avons combiné des textes traditionnels, comme les "Cuadernos de Cortes" et les chroniques, avec d'autres moins utilisés, comme les documents monastiques inédits.

\section{SUMMARY}

A detailed account of the Abbots who attended the various meetings of the "Cortes" celebrated in Castile and Leon, between 1188 and the end of XVIth century, is given in this work. It was at that time that the heads of monasteries stopped attending these assemblys for ecclesiastical reasons, in order to do it exclusively for discharging the duties of their political and administrative jobs. The traditional sources, like "Cuadernos de Cortes" and royal chronicles have been combined with other sources of less frequent use like documents proceeding from the various monastic communities, or the information afforded by the XVIIXIX century. 